\title{
Interaction Characteristics Governing the Synthesis of Magnetite Nanoparticls-conjugated Poly (amido amine) Dendrimer-based Rice Straw Ash
}

\author{
S. A. Hassan\#, A. S. Darwish, Nour E. A. Abed-Elsatar, \\ Heba A. Gobara* and Safaa A. Rushdy \\ Department of Chemistry, Faculty of Science, Ain Shams \\ University, Abbassia 11566, Cairo and "Catalysis Department, \\ Refining Division, Egyptian Petroleum Research Institute, Nasr \\ City, 11727, Cairo, Egypt.
}

HE PARENT magnetite NPs@ poly (amido amine) dendrimer
(PAMAM) composite was synthesized through one pot reaction
pathway. Different hybrid nanocomposites of magnetite (M NPs) of
different concentrations $\left(1^{*} 10^{-3}\right.$ and $3 * 10^{-3} \mathrm{M}$ ) conjugated in situ with
dendrimer (PAMAM) @ rice straw ash (RSA) filler were also
synthesized. The finished as-synthesized nanocomposites were
characterized adopting the XRD, BET, FTIR, DLS, SEM and TEM
techniques. The results revealed that magnetite species are conjugated
with dendrimer branches through N-O-Fe linkages. In hybrid M
NPs@PAMAM@RSA nanocomposites, the presence of RSA binder
seemed to encourage the intimate interactions with dendrimer
branches through Si-OH of the ash and Fe-O-N conjugations; carbon
prevailing in composite space appeared almost filling the dendrimer
cavities. The MNPs-anchored-dendrimer existed as dispersed cubic
nanocrystallites embedded in the dendrimer matrix.

Keywords: Poly (amido amine) dendrimer, Magnetite nanoparticle, Rice straw ash and Hybrid nanocomposites.

According to the infinite network theory of Flory, the presence of three dimensional dendritic branching concepts produced four novel types of architectural polymers called dendritic polymers. These classes of dendritic polymers are classified into four subdivided species: (a) random hyperbranched, (b) dendrigrafts, (c) dendrons, and (d) dendrimers. Dendrimers are monodispersed, hyper-branched, polyfunctional polymers encompassing initiator core, interior layers of diverse generations and exterior layers of terminal function groups ${ }^{(1)}$. Dendrimers are also susceptible to exist in various architectural forms, e.g. bowtied, ball-shaped, bola-form, multi-branched, cauliflower, ... etc, like structures. There are few examples of dendritic architectures in the nanoscale such as the glycogen and amylopectin hyperbranched structures that are used for energy storage. The most popular type of dendrimers is the poly (amido-amine) dendrimers (PAMAM) made by Tomalia et al. $(1985)^{(2)}$. Nowadays, more attention has been paid for exploring innovative structures of dendrimers and using them as filters in nanocomposite technology.

\footnotetext{
${ }^{\#}$ Corresponding author, e-mail:salahabdo@yahoo.com
} 
On the other hand rice straw is one of the most agriculture waste produced through milling of rice,burning of which represents a serious problem in riceproducing countries. Rice straw consists of cellulose and amorphous silica as $20 \%$ ash, $38 \%$ cellulose, $22 \%$ lignin, $18 \%$ pentose, and about $2 \%$ of other organic components ${ }^{(14)}$. When the rice straw is burned it gives $10-14 \%$ by its weight ash containing $>90 \%$ of crystalline silica ${ }^{(3)}$ and small amount of other elements. Ashes are used in various applications depending on specified characteristics, such as ceramic industry which requires chemical purity and reactivity for cement and concrete, metal catalysts requiring high surface area and porosity as well as synthesis of porous carbon, silicon carbide and zeolites. Ashes are also used as additives, fillers, oil adsorbents, ... etc ${ }^{(4)}$.

Dendrimes seem to be highly candidated as beneficial support for metal, metal oxide and metal complexes due to their ability to stabilize the metallic particles enhancing the activity and selectivity of metal nanoparticles toward various catalytic processes.

Magnetite $\left(\mathrm{Fe}_{3} \mathrm{O}_{4}\right)$ is the common oxide of magnetic iron, which possesses a cubic inverse spinal structure. Synthetic magnetite nanoparticles have wide applications due to their unique magnetic properties associated with uniform distribution. Magnetite NPs are used also in catalysis as well as biomedical applications such as enzyme immobilization, anticancer and magnetic resonance ${ }^{(5)}$.

The present study was undertaken to follow up the interaction characteristics governing the synthesis events of a new developed type of magnetite (M) NPs @ poly amidoamine (PAMAM) dendrimer@ rice straw ash (RSA) nanocomposite to be standardized for further applications of industrial and environmental impacts.

\section{Experimental}

\section{Synthesis of PAMAM dendrimers}

Synthesis of $(\mathrm{G}=2)$ star PAMAM- $\left(\mathrm{NH}_{2}\right)_{16}$

To a vigorously stirred solution of ethylenediamine $(476.37 \mathrm{~g}, 524.06 \mathrm{ml}$, $7939.55 \mathrm{mmol})$ in methanol, a solution of star PAMAM (COOMe $)_{16}(\mathrm{G}=1.5)(50 \mathrm{~g}$, $17.83 \mathrm{mmol}$ ) was added under nitrogen at $0^{\circ} \mathrm{C}$ over a period of $2 \mathrm{hr}{ }^{(6)}$. The solution was allowed to warm to room temperature and stirred for further $96 \mathrm{hr}$. The product was purified by using azeotropic mixture of toluene/methanol $=9: 1$ under vacuum at $40^{\circ} \mathrm{C}$, giving a deep yellow oily product (star PAMAM-NH $)_{16}{ }^{(2)}$.

\section{Preparation of rice straw ash (RSA)}

The collected rice straw (from Kafr El-Zayat region) was thoroughly washed with distilled water to remove adhering soil and clay and sieved to 250-500 $\mu \mathrm{m}$. The ash was obtained through controlled burning in a temperature-programmed oven at $600^{\circ} \mathrm{C}$ for $4 \mathrm{hr}$.

\section{Synthesis of pure magnetite nanoparticles}

In $125 \mathrm{ml}$ Erlenmeyer flask, $(2 \mathrm{~g})$ of ferrous sulfate $\mathrm{FeSO}_{4} \cdot 7 \mathrm{H}_{2} \mathrm{O}(99 \%$ Aldrich) and $(5 \mathrm{~g})$ ferric chloride $\mathrm{FeCl}_{3} \cdot 6 \mathrm{H}_{2} \mathrm{O}(99 \%$-Aldrich) were dissolved in 
$25 \mathrm{ml}$ distilled $\mathrm{H}_{2} \mathrm{O}$ (PAMAM@RSA). Thereafter, $0.85 \mathrm{ml}$ of conc. $\mathrm{HCl}$ was added to this mixture under vigorous mechanical stirring. A solution of $\mathrm{NaOH}$ $\left(2 \mathrm{M}, 250 \mathrm{ml} \mathrm{H}_{2} \mathrm{O}\right.$ ) was added dropwise till a black precipitate was formed $(\mathrm{pH}$ 14). The produced NPs were collected by means of a magnet.

Synthesis of the mother(M NPs@PAMAM)nanocomposite

In a $250 \mathrm{ml}$ flask, $(0.00834 \mathrm{gm})$ of ferrous sulphate $\mathrm{FeSO}_{4} .7 \mathrm{H}_{2} \mathrm{O},(0.0216 \mathrm{~g})$ of $\mathrm{FeCl}_{3} \cdot 6 \mathrm{H}_{2} \mathrm{O}$ and a stoichiometric amount of PAMAM dendrimer $(\mathrm{G}=2,1 \mathrm{~g})$, in a molar ratio of precursor/dendrimer $=1: 20$, were dissolved in $25 \mathrm{ml}$ of distilled water, then $0.004 \mathrm{ml}$ of conc $\mathrm{HCl}$ was added. A solution of $\mathrm{NaOH}(1 \mathrm{M}, 4 \mathrm{~g}, 50 \mathrm{ml}$ $\mathrm{H}_{2} \mathrm{O}$ ) was added dropwise with stirring till a black precipitate was formed $(\mathrm{pH} \sim$ 14). The produced NPs were collected by a magnet.

Preparation of magnetite-rice straw ash-PAMAM dendrimernanocomposite

A $6.5 \mathrm{~g}$ of dry rice straw ash (RSA) was slowly added to PAMAM dendrimer $(\mathrm{G}=2,1 \mathrm{~g})$ dissolved in $10 \mathrm{ml}$ of isopropanol. $0.00139 \mathrm{~g}$ of ferrous sulfate, $\mathrm{FeSO}_{4} .7 \mathrm{H}_{2} \mathrm{O}$, and $50.0360 \mathrm{~g}$ of ferric chloride, $\mathrm{FeCl}_{3} \cdot 6 \mathrm{H}_{2} \mathrm{O}$, in $10 \mathrm{ml}$ of $0.2 \mathrm{M} \mathrm{HCl}$ were mixed with the PAMAM@RSA composite with boiling under vigorous stirring. $\mathrm{NaOH}\left(2 \mathrm{M}, 250 \mathrm{ml} \mathrm{H}_{2} \mathrm{O}\right)$ was added dropwise till ( $\left.\mathrm{pH} \sim 14\right)$. The mixture was stirred at room temperature for $24 \mathrm{hr}$, after which it was left to stand then decanted, filtered and washed several times with $\mathrm{H}_{2} \mathrm{O}$ and then with acetone.

\section{Characterization techniques}

The as-synthesized nanocomposites were characterized via FT-IR spectra, recorded on a JASCO spectrophotometer model FT/IR-420, using KBr disc technique in the wave number range of 4000 to $200 \mathrm{~cm}^{-1}$. Proton nuclear magnetic resonance $\left({ }^{1} \mathrm{H}-\mathrm{NMR}\right)$ spectra were measured on a Varian Mercury 300 $(300 \mathrm{MHz})$ instrument.The crystalline structure and the different phases were investigated via X-ray diffraction analysis (XRD) using Shimadzu XD-1 diffractometer. The phase identification was made according to the Joint Committee on Powder Diffraction Standards (JCPDS). The crystallite size, D-XRD was calculated according to Scherer equation ${ }^{(7)}$.

$$
D_{X R D}=\frac{K \lambda}{\beta \cos (\theta)}
$$

where $\mathrm{k}$ is the Sherrer constant (0.89), $\lambda$ is the wavelength of the X-ray radiation $(0.15418 \mathrm{~nm}$ for $\mathrm{Cu} \mathrm{K \alpha}), \beta$ is the full width at half maximum (FWHM) of the diffraction peak measured at $2 \theta$, and $\theta$ is the diffraction angle. The textural properties were followed up using the $\mathrm{N}_{2}$ adsorption-desorption isotherms measured at $-196^{\circ} \mathrm{C}$ using NOVA-2000 gas sorption analyzer. The morphology of the synthesized nanocomposites was investigated via JSM 7500FA- High Resolution Cold Field Emission SEM and by transmission electron microscopy (TEM) via JEM 1011. The size and electrokinetic potential were measured using a Nano Series Zeta Sizer, Malvern; Worcestershire, UK. The particle size distribution and hydrodynamic diameter of different nanocomposites were evaluated through Dynamic Light Scattering (DLS). Each sample $(0.5 \mathrm{mg} / \mathrm{ml})$ was suspended in deionized water and ultrasound-irradiated for $5 \mathrm{~min}$. The suspension 
was then kept at room temperaturefor $24 \mathrm{hr}$ under vigorous stirring. The $\mathrm{pH}$ was then adjusted at 7.4 and zeta potential values were evaluated at $30^{\circ} \mathrm{C}$. All measurements were performed for five replicates and averaged to get the final value.

\section{Results and Discussion}

Physicochemical characteristics of PAMAM dendrimer

$H^{1}$ NMR and $C^{13}$ NMR measurement of PAMAM dendrimers

In this study, the starting PAMAM dendrimer $(\mathrm{G}=1.5)$ was formed by addition of methyl acrylate to $\mathrm{G}=1$, to be terminated by 16 acrylate groups as indicated by $\mathrm{C}^{13}$ NMR spectrum shown in Fig.1. The analysis reveals the following: $\mathrm{C}^{13}$ NMR spectrum (DMSO) $\delta_{\mathrm{C}}: 49.573$ (a), 49.115 (b), 32.419 (c), $37.833(\mathrm{~d}), 51.251(\mathrm{e}), 172.650(\mathrm{x}), 172.764\left(\mathrm{x}_{1}\right), 172.829(\mathrm{y}), 52.016(\mathrm{z})$.

Also, the elemental analysis data of PAMAM dendrimer $(\mathrm{G}=1.5)$ and that one of $(\mathrm{G}=2)$ are summarized in Table 1 .

TABLE 1. Elemental analysis data of PAMAM dendrimer $(G=1.5)$ and that one of $(\mathrm{G}=2)$.

\begin{tabular}{|ccccccc|}
\hline \multirow{2}{*}{ Generation } & \multicolumn{2}{c}{$\mathbf{C \%}$} & \multicolumn{2}{c}{$\mathbf{H \%}$} & \multicolumn{2}{c|}{ N\% } \\
& Found & Calc & Found & Calc & Found & Calc \\
\hline $\begin{array}{c}\mathbf{G}=\mathbf{1 . 5} \\
\mathbf{C}_{\mathbf{1 2 6}} \mathbf{H}_{\mathbf{2 2 6}} \mathbf{N}_{\mathbf{2 6}} \mathbf{O}_{\mathbf{4 4}}\end{array}$ & 54.1 & 53.9 & 8.9 & 8.1 & 14 & 12.9 \\
$\begin{array}{c}\mathbf{G}=\mathbf{2} \\
\mathbf{C}_{\mathbf{1 4 2}} \mathbf{H}_{\mathbf{2 8 8}} \mathbf{N}_{\mathbf{5 8}} \mathbf{O}_{\mathbf{2 8}}\end{array}$ & 48.5 & 52.4 & 9.3 & 8.89 & 22.9 & 24.9 \\
\hline
\end{tabular}

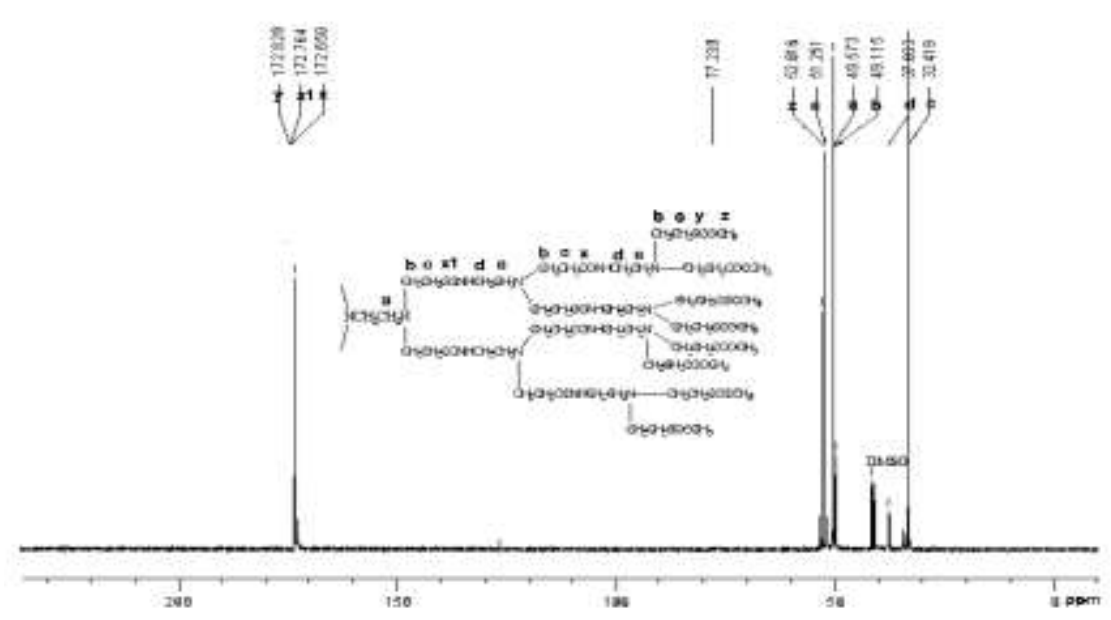

Fig. 1. $\mathrm{C}^{13} \mathrm{NMR}$ dendri-PAMAM $\left(\mathrm{COOCH}_{3}\right)_{16}$. 


\section{FTIR investigation}

FT-IR spectra of the parent PAMAM (poly amido amine dendrimer, $(\mathrm{G}=2)$ as well as the conjugated magnetite-dendrimer (M NPs@PAMAM composite) are depicted in Fig. 2. For PAMAM (G=2) (Fig. 2, a), the peak at $3270 \mathrm{~cm}^{-1}$ is attributed to the bending vibration of primary amine $\left(-\mathrm{NH}_{2}\right)$ and that are at 3059 $\mathrm{cm}^{-1}$ is due to secondary amine (-NH). Also, the two sharp peaks at 1683 and $1584 \mathrm{~cm}^{-1}$ are due to (-CO-NH-) groups. In addition, the weak peak at $1200 \mathrm{~cm}^{-1}$ is referred to (C-C) bending and those the peaks at 1471 and $2830 \mathrm{~cm}^{-1}$ are related to $\left(-\mathrm{CH}_{2}\right)$ groups. However, the characteristic peaks of molecular water are assigned at $3270 \mathrm{~cm}^{-1}$ and $3059 \mathrm{~cm}^{-1}$. For PAMAM dendrimer-conjugated magnetite nanoparticles (M NPs@PAMAM), beside the characteristic peaks of PAMAM two new absorption peaks appeared. The first one at $597 \mathrm{~cm}^{-1}$ is attributable to $\mathrm{Fe}-\mathrm{O}$ of magnetite (intrinsic stretching vibration at tetrahedral site $\mathrm{Fe}_{\text {teta }} \mathrm{O}$ ) and the second one at $1044 \mathrm{~cm}^{-1}$ of $(\mathrm{N}-\mathrm{O})$, which may suggest the overall formation of (N-O-Fe) linkages ${ }^{(8)}$. It is clear that these two peaks (3059 $\mathrm{cm}^{-1}$ of primary amine and $3270 \mathrm{~cm}^{-1}$ of secondary amine) are subject of masking (overlapping) with a somewhat shifted broad peak maximized at $3442 \mathrm{~cm}^{-1}$ assigned most probably to the molecular water in magnetite moieties ${ }^{(9)}$.

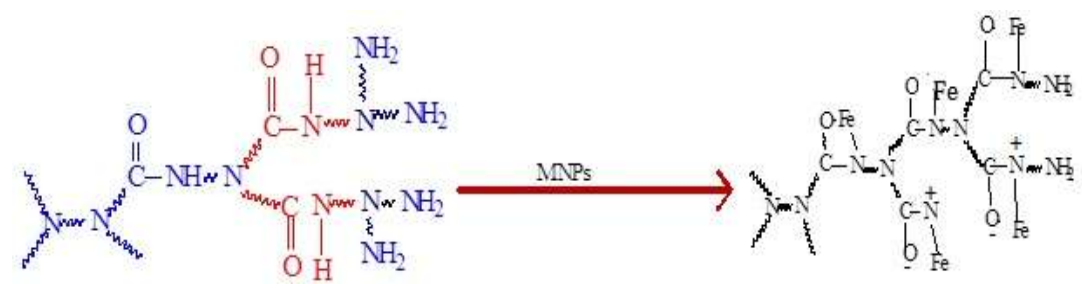

Scheme 1.Proposed mechanism of the formation of (M NPs@PAMAM).

The FT-IR spectra of RSA and $\left(3 * 10^{-3} \mathrm{M}\right)$ M NPs @ PAMAM @ RS Ananocomposite are represented in Fig. 2(b). For neat RSA the broad peak at $480-460 \mathrm{~cm}^{-1}$ is assigned to $\mathrm{Si}-\mathrm{O}-\mathrm{Si}$ bending characterizing the amorphous silica content. The peak at $1030 \mathrm{~cm}^{-1}$ is referred to $\mathrm{SiO}_{2}$ lattice vibration and that one at $3867 \mathrm{~cm}^{-1}$ is related to $(v \mathrm{O}-\mathrm{H})$ vibration. The weak peaks in the range of $1340-1490 \mathrm{~cm}^{-1}$ seem to be due to $-\mathrm{CH}_{2^{-}}, \mathrm{CH}_{3}$ and $\mathrm{COOH}$ vibrations arisen from carbon-content of the ash. For the M NPs@PAMAM@RSA system, the peak at $465 \mathrm{~cm}^{-1}$ belongs to the bending vibration of [v (O-Si-O)] of RSA. Also, the peaks at $1074 \mathrm{~cm}^{-1}$ and $790 \mathrm{~cm}^{-1}$ are assigned to [ $v$ (Si-O-Si)] stretching vibration modes of RSA; becoming more pronounced than the corresponding ones in the original sample of RSA. The characteristic peak shifted at $618 \mathrm{~cm}^{-1}$ eviedently belongs to magnetite $(\mathrm{Fe}-\mathrm{O})$. It is to be mentioned that the peak at $1638 \mathrm{~cm}^{-1}$ in the nanocomposite is assigned to the -CO-NH- groups of PAMAM, while that new one at $1738 \mathrm{~cm}^{-1}$ may refer to formation of Fe-O-N bond with the dendrimer (Scheme 1). In this regard, the broad peak at $3565 \mathrm{~cm}^{-1}$ is corresponding to water content in both magnetite and RSA in M NPs@PAMAM@RSA composite. 

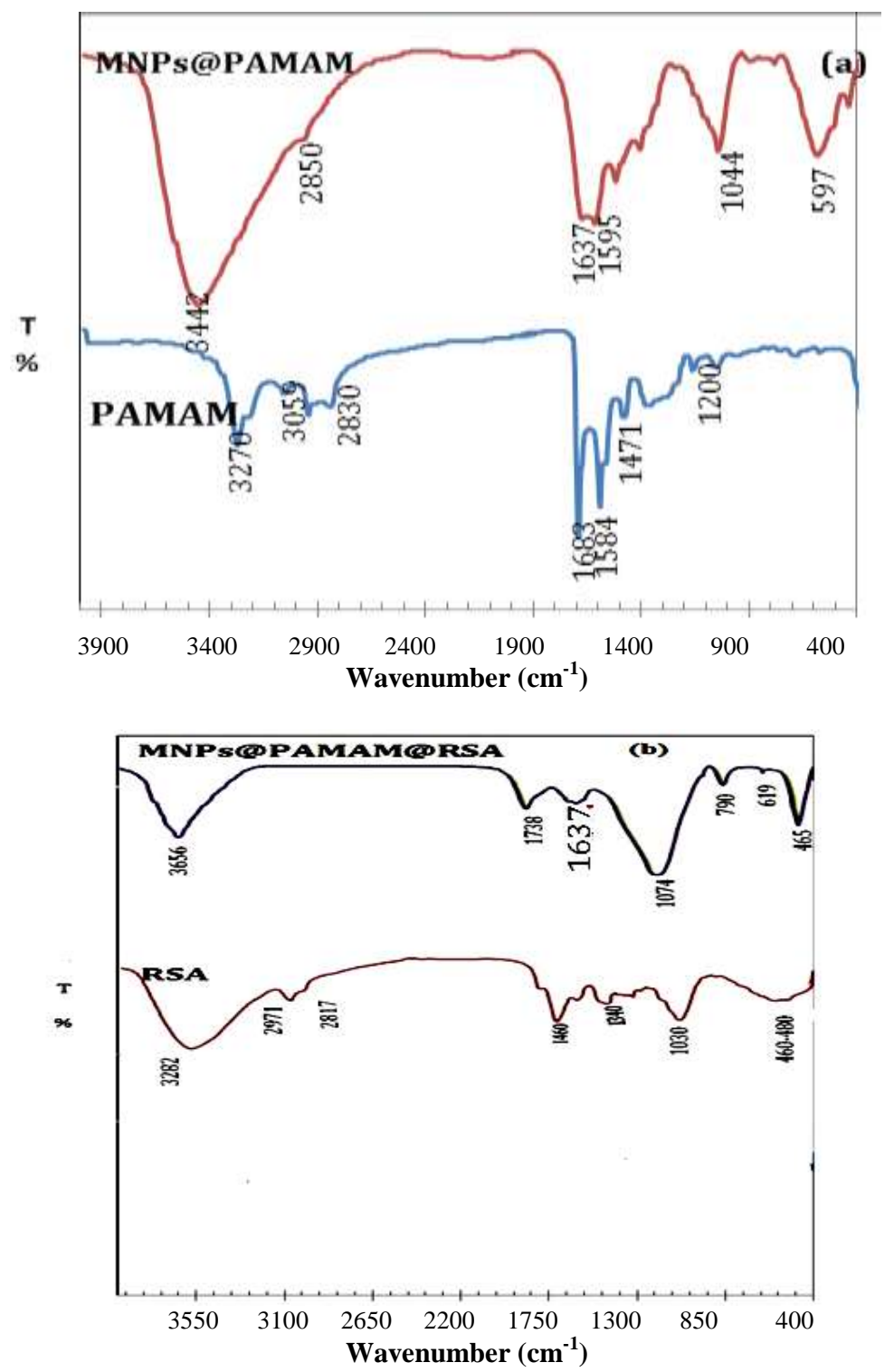

Fig. 2. FT-IR spectra of (a) PAMAM and M NPs @PAMAM and (b) RSA and M NPs $\left(3^{*} 10^{-3} M\right)$ M NPs@PAMAM@RSA. 


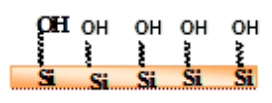

Silica surface

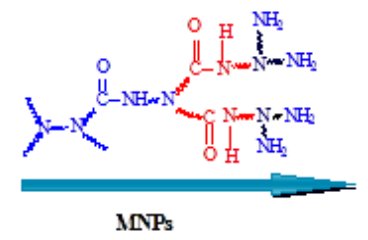

MNPs

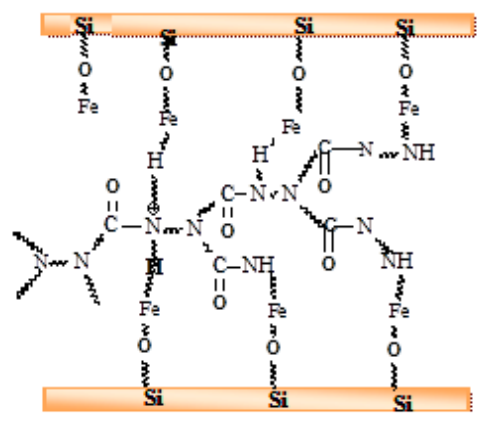

Scheme 2.Proposed mechanism of the formation of (M NPs@PAMAM@RSA).

\section{$X R D$ analysis}

The XRD pattern illustrated in Fig. 3 (a) for pure magnetite nanoparticles shows characteristic peaks at $2 \theta=18.4^{\circ}, 29.4^{\circ}, 35.1^{\circ}, 42.5^{\circ}, 52.8^{\circ}, 55.5^{\circ}$, and $75.6^{\circ}$ corresponding to (111), (220), (311),(400), (422), (511), and (533) Miller indices with lattice spacings (d): 4.8, 3.0, 2.5, 2.1, 1.37, 1.65 and $1.25 \mathrm{~nm}$, respectively. The position and relative intensity of the peaks in the obtained pattern agree well with those of magnetite (JCPDS card No 89-0691). This indicates that magnetite in this study has an inverse spinel structure with a face centered cubic form ${ }^{(10)}$. In addition, all the characteristic peaks typical of $\gamma-\mathrm{Fe}_{2} \mathrm{O}_{3}$ and $\alpha-\mathrm{Fe}_{2} \mathrm{O}_{3}$ are neglected in the present study to simplify the comparison of different synthesis parameters.

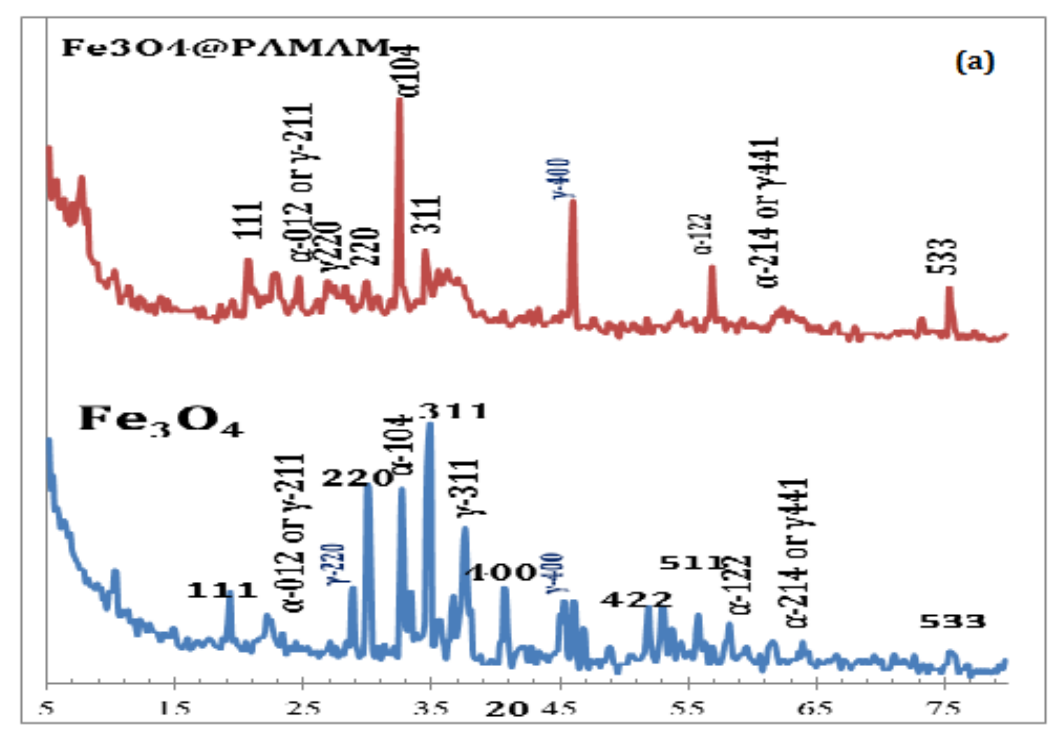

Egypt. J. Chem. 58, No. 6 (2015) 


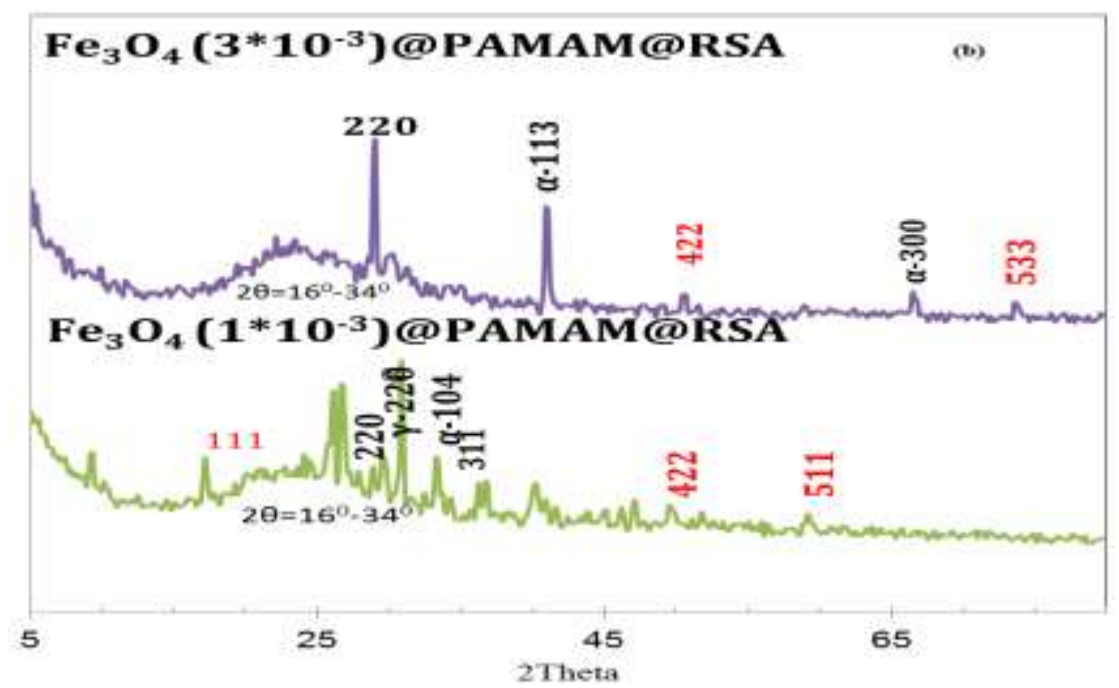

Fig. 3. XRD patterns of (a) pure M NPs and parent M NPs @PAMAM nanocomposite and (b) M NPs $\left(1 * 10^{-3} M\right.$ and $\left.1 * 10^{-3} M\right) @$ PAMAM@RSA.

The mean crystallite size of pure magnetite $\left(\mathrm{D}_{\mathrm{XRD}}\right)$ determined by Scherrer equation (Table 2) was found to be 35.1, 42.8, 39.1, 37, 34.2, 39.1 and $23.1 \mathrm{~nm}$ corresponding to (111), (220), (311), (400), (422),(511) and (533) of magnetite facets, respectively. For the comparative purposes, the average particle sizes calculated for M NPs at $2 \theta=35.1^{\circ}$ (311) and $55.5^{\circ}$ (511) being equal (viz., 39.1 $\mathrm{nm})$ will be taken as reference for the other composite systems.

TABLE 2. XRD data and particle size calculated from Scherrer equation for M NPs and the mother M NPs@PAMAMnanocomposite.

\begin{tabular}{ccccc}
\hline System & $\mathbf{2 \theta}$ & $\begin{array}{c}\mathbf{F e}_{\mathbf{3}} \mathbf{O}_{\mathbf{4}} \\
(\mathbf{h ~ k ~} \mathbf{~})\end{array}$ & $\begin{array}{c}\text { Particle size } \\
(\mathbf{n m})\end{array}$ & d-Spacing \\
\hline \multirow{2}{*}{$\mathbf{F e}_{\mathbf{3}} \mathbf{O}_{\mathbf{4}}$ (M NPs) } & 18.4 & 111 & 35.1 & 4.8 \\
& 29.4 & 220 & 42.8 & 3.0 \\
& 35.1 & 311 & 39.1 & 2.5 \\
& 42.5 & 400 & 37 & 2.1 \\
& 52.8 & 422 & 34.2 & 1.7 \\
$\mathbf{F e}_{3} \mathbf{O}_{\mathbf{4}}$ PAMAM & 55.5 & 511 & 39.1 & 1.3 \\
& 75.6 & 533 & 23.1 & 1.2 \\
\hline & 18.4 & 111 & 34.2 & 4.4 \\
& 29.4 & 220 & 28.5 & 2.0 \\
& 35.1 & 311 & 27.7 & \\
& 52.8 & 422 & Disappeared & \\
\hline
\end{tabular}

Egypt. J. Chem. 58, No. 6 (2015) 
By comparing the patterns of magnetite in the mother M NPs@PAMAM composite with that of pure magnetite reference sample, it can be seen clearly that the average crystallite sizes of M NPs have been reduced in the synthesized composite (M NPs@ PAMAM), viz., with the following extents: $0.9 \mathrm{~nm}$ at $2 \theta=18.4^{\circ}(111), 14.3 \mathrm{~nm}$ at $2 \theta=29.4^{\circ}(220)$ and $16.4 \mathrm{~nm}$ at $2 \theta=35.1^{\circ}(311)$. In view of disappearance of M NPs peak at $2 \theta=55.5^{\circ}(511)$ in the parent composite, one can conclude that magnetite has been interacted with PAMAM, i.e. most probably through bulk CO-NH linkages in cavities. The M NPs are incorporated in the PAMAM matrix as encapsulated species of markedly reduced average sizes.

The XRD diffraction patterns of M NPs@PAMAM@RSA system with two different ratios of magnetite $\left(1 * 10^{-3}\right.$ and $\left.3 * 10^{-3}\right)$ are illustrated in Fig. 3. All samples show a broad hump in the $2 \theta$ ranging from $16^{\circ}$ to $34^{\circ}$ related most probably to the amorphous silica phase in RSA. For M NPs@PAMAM@RSA $\left(1 * 10^{-3}\right)$ system, in addition to amorphous silica phase, the peaks at $2 \theta=18.1^{\circ}$, $29.6^{\circ}, 35.1,52.3^{\circ}$ and $75.6^{\circ}$ corresponding (111), (220), (311), (422) and (533) Miller indices of magnetiteare observed. The corresponding reduction extents in average crystallite sizes of $\mathrm{Fe}_{3} \mathrm{O}_{4}$ are 18.0, 16.5, 25.8 and $18.7 \mathrm{~nm}$ at corresponding (111), (220), (311) and (422), respectively. The peak at $75.6^{\circ}$ (533) disappeared indicating the evident interaction of M NPs during its conjugation with the RSA-PAMAM network.

For the M NPs@PAMAM@RSA $\left(3 * 10^{-3} \mathrm{M}\right)$ system, the same reduction trend in average crystallite sizes was obtained at (422) and (511), together with disappearance of the peak at $35.1^{\circ}(311)$.

In conclusion, it is noticed that the particle size of pure magnetite is decreased due to its encapsulation in PAMAM dendrimermatrix and continues to decrease through anchorage to RSA.

TABLE 3. XRD data and particle size calculated from Scherrer equation for M NPs@PAMAM@RSA $\left(1 * 10^{-3} M\right)$ and the M NPs@PAMAM@RSA $\left(3 * 10^{-3} \mathrm{M}\right)$ nanocomposites.

\begin{tabular}{|c|c|c|c|c|}
\hline System & $2 \theta$ & $\begin{array}{l}\text { Fe3O4 } \\
(\text { h k l) }\end{array}$ & $\begin{array}{c}\text { Particle size } \\
\text { (nm) }\end{array}$ & d-Spacing \\
\hline \multirow{5}{*}{$\begin{array}{c}\text { Fe3O4@PAMAM@RSA } \\
(1 * 10-3 M)\end{array}$} & 18.1 & 111 & 17.1 & 4.9 \\
\hline & 29.6 & 220 & 26.3 & 3 \\
\hline & 35.1 & 311 & 13.3 & 1.2 \\
\hline & 52.3 & 422 & 15.5 & 1.7 \\
\hline & 75.6 & 533 & Disappeared & \\
\hline \multirow{5}{*}{$\begin{array}{c}\text { Fe3O4@PAMAM@RSA } \\
(3 * 10-3 M)\end{array}$} & 29.6 & 220 & 11.2 & \multirow{5}{*}{1.6} \\
\hline & 35.1 & 311 & Disappeared & \\
\hline & 52.5 & 422 & 7.7 & \\
\hline & 55.2 & 511 & 53.6 & \\
\hline & 75.6 & 533 & & \\
\hline
\end{tabular}




\section{Surface study}

Inspection of Table 4 indicates that M NPs@PAMAM exhibits noticeably small surface area $\left(7.8 \mathrm{~m}^{2} / \mathrm{g}\right)$. This may be linked with the anchorage of M NPs to the $-\mathrm{NH} \&-\mathrm{C}=\mathrm{O}$ sites of PAMAM dendrimermain core ${ }^{(11)}$. By adding RSA (of $\mathrm{S}_{\mathrm{BET}}=14.5 \mathrm{~m}_{2} / \mathrm{g}$ ) ${ }^{(14)}$, the produced composite M NPs @PAMAM@RSA shows some increase in surface area, viz, $9.4 \mathrm{~m}^{2} / \mathrm{g}$, arising from both the pore system of RSA and cavity structure of PAMAM.

TABLE 4. Surface area parameters of M NPs@PAMAM and $\left(1 * 10^{-3} M\right.$ and $3 * 10^{-3}$ M) M NPs@PAMAM@RSA nanocomposites.

\begin{tabular}{|c|c|c|c|c|c|c|}
\hline Adsorb & $\mathbf{C}_{\text {BET }}$ & $\begin{array}{c}\mathrm{Vm} \\
\mathrm{Cm}^{3} / \mathrm{g}\end{array}$ & $\begin{array}{c}\mathbf{S}_{\text {BET }} \\
\left(\mathrm{m}^{2} / \mathrm{g}\right)\end{array}$ & $\begin{array}{c}\text { Total } \\
\text { pore } \\
\text { volume } \\
\left(\mathbf{V}_{\mathbf{p}}\right) \\
(\mathrm{ml} / \mathrm{g})\end{array}$ & $\begin{array}{c}\text { Average } \\
\text { pore } \\
\text { radius } \\
\left(\mathbf{r}_{\mathbf{p}}\right)(\AA)\end{array}$ & $\begin{array}{c}\text { Most } \\
\text { abundance } \\
\text { approximate } \\
\text { pore radius } \\
\left(\mathbf{r}_{\text {m.abund }}\right)(\mathbf{n m})\end{array}$ \\
\hline M NPs@PAMAM & 11.3 & 1.7 & 7.8 & 0.0280 & 74.1 & 3.7 \\
\hline M NPs(1*103)@PAMAM@RSA & 8.9 & 2.1 & 9.4 & 0.0184 & 38.9 & 1.7 \\
\hline 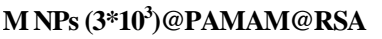 & 5.6 & 1.3 & 5.8 & 0.0155 & 54.5 & 1.6 \\
\hline
\end{tabular}

To confirm the overall pore system of the finished composite, the pore parameters of the components can be compared. The pore system of M NPs @PAMAM represents dendrimer cavities of average pore radius $7.4 \mathrm{~nm}$ (wide pores), with total pore volume of $0.028 \mathrm{~cm}^{3} / \mathrm{g}$, while the pore system of RSA represents narrower mesopores of $1.4 \mathrm{~nm}$ with larger pore depth of $0.074 \mathrm{~cm}^{3} / \mathrm{g}$, reflecting the mixed pore structure of the ash.

For M NPs@PAMAM@RSA, the average pore radius is 3.9 nm, i.e., with a considerable decrease in the cavities parameters $\left(\mathrm{r}_{\mathrm{p}}\right.$ from $7.4 \mathrm{~nm}$ to $3.9 \mathrm{~nm}$ and $\mathrm{v}_{\mathrm{p}}$ from $0.028 \mathrm{~cm}^{3} / \mathrm{g}$ to $0.018 \mathrm{~cm}^{3} / \mathrm{g}$ ) linked with some filling by RSA particles. On the other hand, the increase in RSA pore radius (from $1.4 \mathrm{~nm}$ to $3.9 \mathrm{~nm}$ ) confirms the coverage and filling process $\left(c f\right.$., the change of $\mathrm{v}_{\mathrm{p}}$ from 0.074 to 0.018 ). The obtained results are well documented by the pore size distribution (PSD) curves in Fig. 4.

Dynamic light scattering (DLS) study for MNPs @ PAMAM

Zeta potential (ל) study

The zeta potential data measured at $\mathrm{pH} 4$ and 9 are summarized in Table 5, while the hydrodynamic particle size distributions are illustrated in Fig.5. For the mother M NPs@PAMAM, the zeta potential $(\zeta)$ measured in acidic medium $(\mathrm{pH}=4)$ is $(+4.09 \mathrm{mV})$, referring to the retained positively charged $\mathrm{NH}$-groups in the dendrimer core, overcoming in the same time the negative charges of magnetite nanoparticles (M NPs). In the basic medium, $\mathrm{pH}=9$, $\zeta$ is highly negative $(-25.7 \mathrm{mV})$, i.e., referring to the magnetite particulates exposed on the dendrimer surface.

Egypt. J. Chem. 58, No. 6 (2015) 


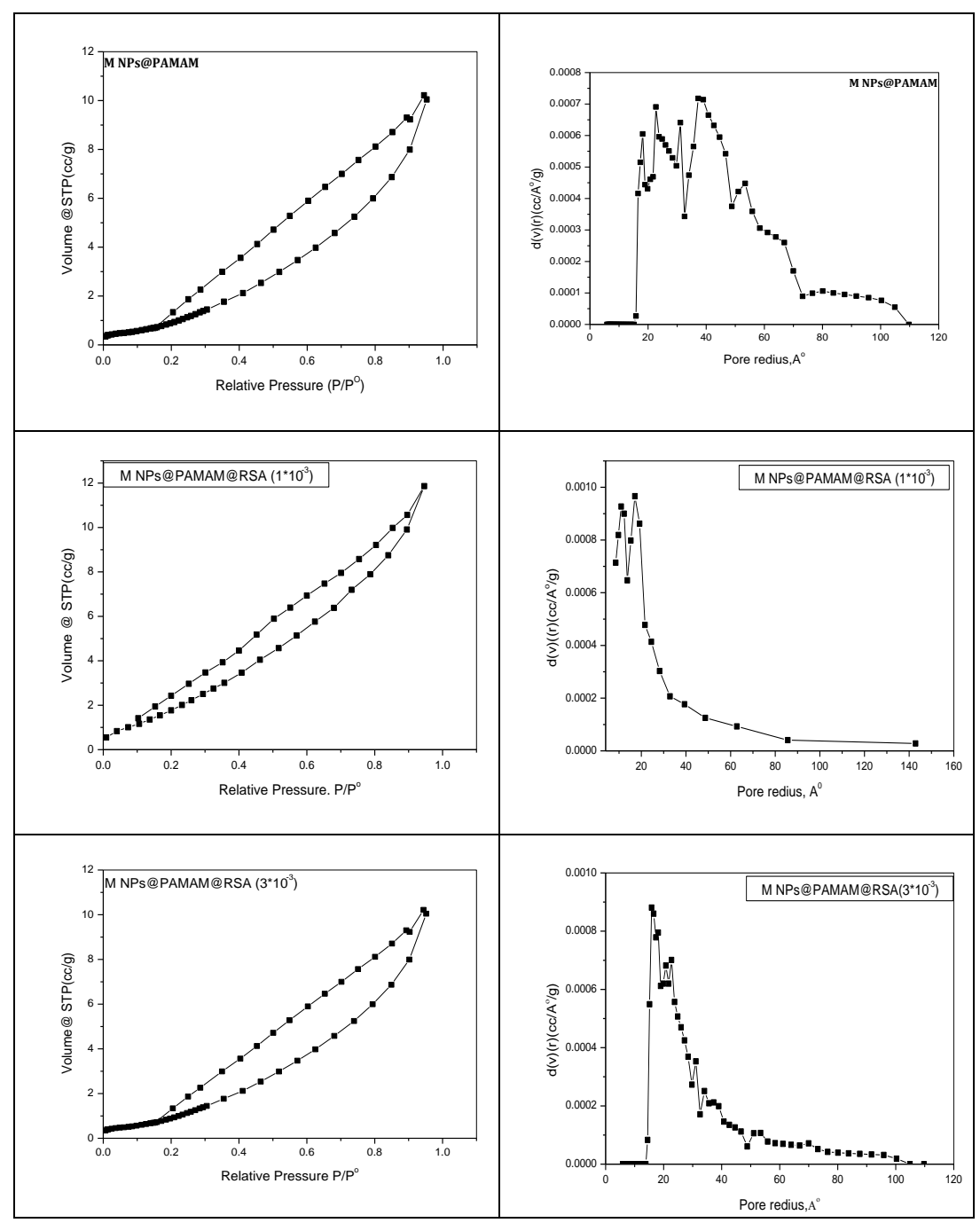

Fig. 4. $\mathrm{N}_{2}$-Adsortion-desorption isotherms and particle size distribution (nm) of parent M NPs @PAMAM nanocomposite and M NPs $\left(1 * 10^{-3} M\right.$ and $1 * 10^{-}$ ${ }^{3}$ M) @PAMAM@RSA.M NPs@PAMAM.

For the $\left(1 * 10^{-3} \mathrm{M}\right)$ M NPs@PAMAM@RSA composite, the $\zeta$ value is -12.5 $\mathrm{mV}($ at $\mathrm{pH}=4)$, i.e., an apparent decrease in $\zeta$ of the mother M NPs @PAMAM is evident. This may confirm the suggested interaction profile of RSA (through $\mathrm{Si}-\mathrm{O}$ site) with the terminal groups amines of the dendrimer branches, rather 
than with M NPs sited at the core, leaving some negatively charged magnetite nanoparticlesbe exposed.

TABLE 5. DLS and zeta potential parameters of M NPs@PAMAM and $\left(1 * 10^{-3} \mathrm{M}\right.$ and $3 * 10^{-3}$ M) M NPs@PAMAM@RSAnanocomposites.

\begin{tabular}{|c|c|c|c|c|}
\hline \multirow[t]{2}{*}{ Composites } & \multicolumn{2}{|c|}{$\begin{array}{c}\text { Zeta potential }(\zeta) \\
(\mathrm{mV})\end{array}$} & \multicolumn{2}{|c|}{$\begin{array}{l}\text { Conductivity } \\
\left(\mu \mathrm{S} / \mathrm{cm}^{-1}\right)\end{array}$} \\
\hline & $\mathrm{pH}=4$ & $\mathrm{pH}=9$ & $\mathrm{pH}=4$ & $\mathrm{pH}=9$ \\
\hline M NPs@PAMAM & 4.09 & -25.7 & 4.71 & 6.99 \\
\hline M NPs(1*103M)@PAMAM@RSA & -12.5 & -28.7 & 4.75 & 6.73 \\
\hline M NPs(3*103M)@PAMAM@RSA & -5.52 & -25.5 & 4.51 & 6.86 \\
\hline
\end{tabular}

The mother M NPs@PAMAM
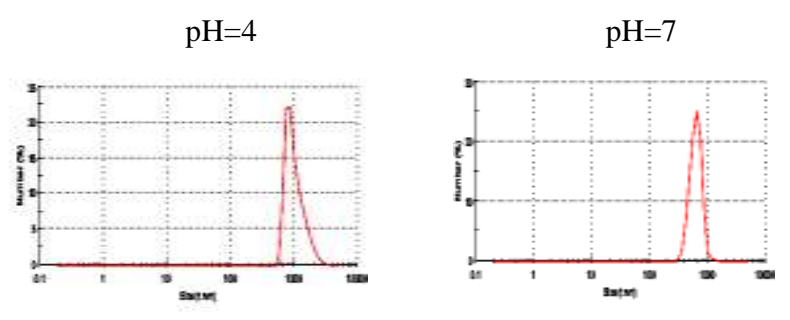

M NPs $\left(1 * 10^{-3}\right) @$ PAMAM@RSA
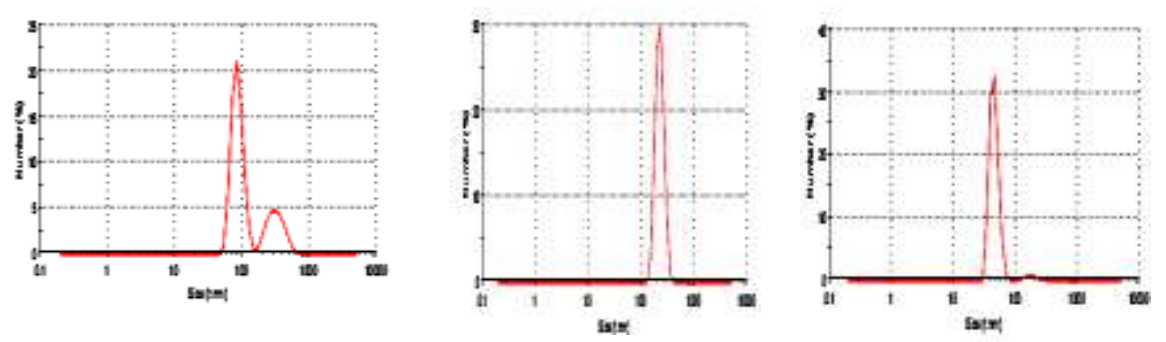

M NPs $\left(3 * 10^{-3}\right) @$ PAMAM@RSA
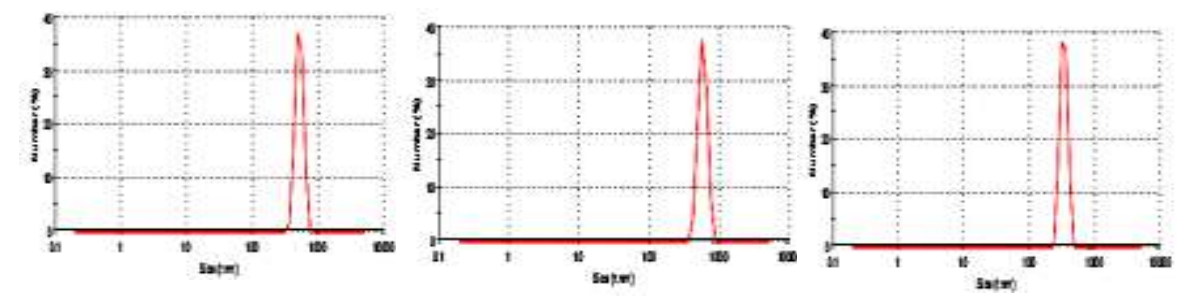

Fig. 5. Hydrodynamic particle size distribution profiles of different nanocomposite.

Egypt. J. Chem. 58, No. 6 (2015) 
On the contrary, when the M NPs concentration increases to $3 * 10^{-3} \mathrm{M}$ (at $\mathrm{pH}=4$ ), the RSA seems to interact not only with the branch amine of dendrimer but also with the excess M NPs exposed on the dendrimer surface. Thus, the charge tends to be positive $(\zeta+5.52)$ approaching that of the mother M NPs@PAMAM. Again at $\mathrm{pH}=9$, the increase in basicity may be reflected in the more negative charges (or $\zeta-28.7$ and -25.2)following the same mechanism described for the different concentrations. Such increase in the basicity may be linked with the expansion of the electric double layer (high negative charge density).

Particle size distribution (PSD) study

For the hydrodynamic particle size distributions represented in Fig. 5, it is clear that the average particle size of this M NPs@PAMAM is decreased gradually and markedly from $1032 \mathrm{~nm}$ to $300 \mathrm{~nm}$ by increasing the $\mathrm{pH}$ value of the solution from 0.4 to 0.9 ; the colloidal M NPs tending to be more stable especially in alkaline medium. Such behavior is in compliance with rising of zeta-potential values (more -ve), i.e., expressing the repulsive forces between $\mathrm{M}$ NPs@PAMAM colloidal particles.

For the $\left(1 * 10^{-3}\right.$ M) M NPs@PAMAM@RSA composite, the increase of solution $\mathrm{pH}$ is accompanied by a decrease in average particle size achieving 45 $\mathrm{nm}($ at $\mathrm{pH}=9)$, linked probably with more pronounced repulsion forces and $\zeta$ values. On the other hand, the presence of RSA as co-binding component seems to encourage the intimate interaction with the dendrimer in favor of the M NPs. As an evidence for this behavior, at $\mathrm{pH}=4$, the bimodal particle size distribution may point to the intimate interaction of RSA with the dendrimer. By increasing the concentration of M NPs to $3 * 10^{-3} \mathrm{M}$, the same trend of particle size reduction is observed (from $512 \mathrm{~nm}$ to $332 \mathrm{~nm}$ ) by increasing the $\mathrm{pH}$ value up to 9 .

\section{TEM study}

The morphology and dispersion of M NPs in mother M NPs@PAMAM nanocomposite are represented in Fig. 6 (a). The dendrimer branches are seen as separate stacks, distributed in some organized shape. The magnetite nanoparticles are located mainly on the dendrimer branches and in their cavities in an uneven dispersion profile with average particle sizes 4, 6 and $10 \mathrm{~nm}$.

For $\left(1 * 10^{-3} \mathrm{M}\right) @$ PAMAM@RSA (Fig. 6, b), it is evident that the magnetite cubic nanocrystallites are dispersed mainly on dendrimer network having average sizes ranged between $35-52 \mathrm{~nm}$, covering also most of the cavities.

For the higher concentration $\left(3 * 10^{-3} \mathrm{M}\right) @$ PAMAM@RSA(Fig. 6, c and d)), the images show the embedded M NPs in some cubic structure together with the major dispersion of small dots (image c), clearly linked through the intimate interaction between RSA and PAMAM matrix. This type of interaction is more pronounced in image (d) where the whole structure of the nanocomposite is associated with anchorage of well dispersed M NPs in even distribution between the RSA and PAMAM phases. 


\section{SEM study}

The SEM images of different PAMAM-base composites under study are shown in Fig. 7. The images ( $a$ and b) of mother M NPs@PAMAM, indicate the even distribution of M NPs over PAMAM blocks. Some of them are introduced into the dendrimer cavities as accumulated bright pellets. For $\left(3 * 10^{-3}\right.$ M)@PAMAM@RSA, the images ( $\mathrm{c}$ and $\mathrm{d}$ ) reveal the whole network of PAMAM, majoring as a field, with organized fine granules and well attached sets intimately interacted with RSA sticks. The M NPs are distributed evenly in this interaction phases (c). The protrusions of PAMAM, intimately interacted with covering RSA sticks and with magnetite needles and dots, are well documented in the highly magnified image (d).

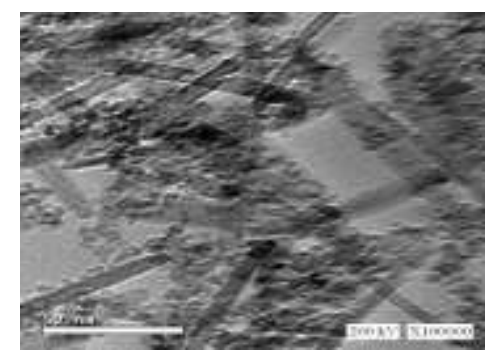

(a)

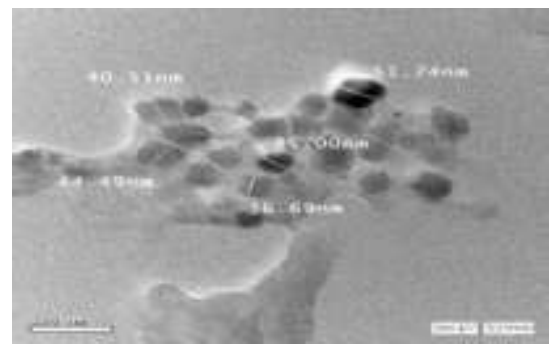

(b)

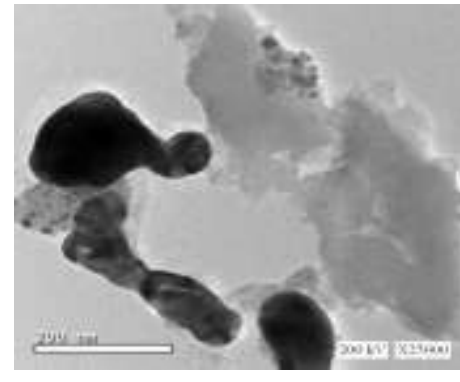

(c)

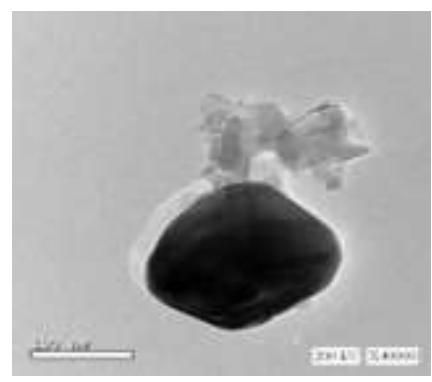

(d)

Fig. 6 (a). TEM images of M NPs@PAMAMnanocomposite, (b) M NPs $\left(1 * 10^{-3} \mathrm{M}\right)$ @PAMAM@ RSA nanocomposite and (c, d) M NPs $\left(3 * 10^{-3}\right.$ M) @PAMAM@RSA nanocomposite.

Egypt. J. Chem. 58, No. 6 (2015) 


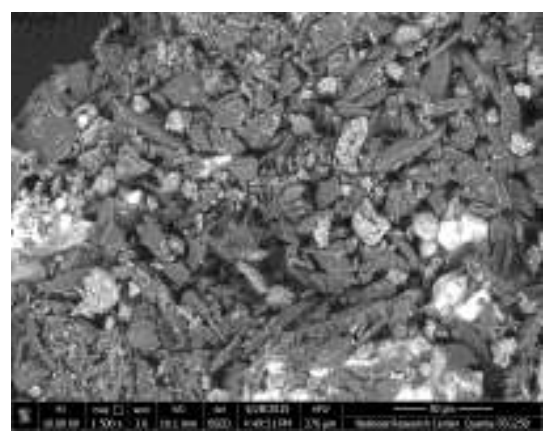

(a)

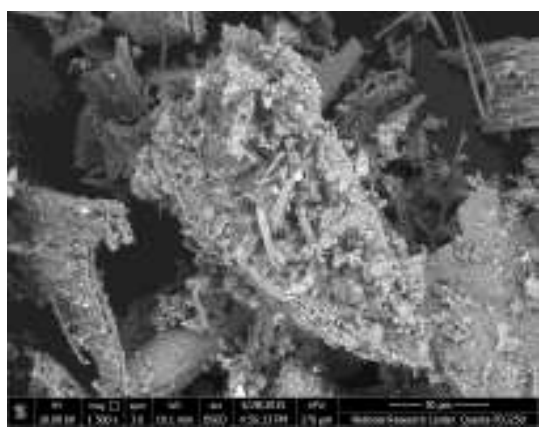

(c)

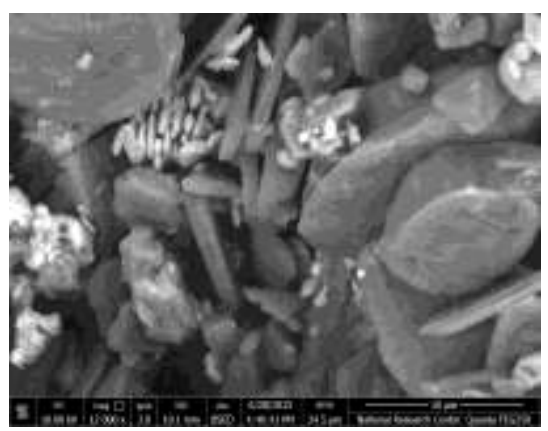

(b)

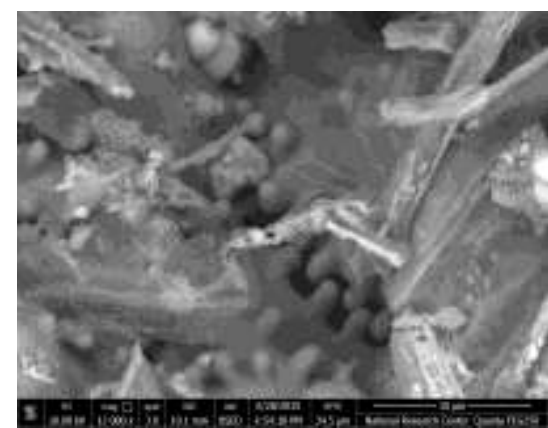

(d)

Fig. 7. SEM images of M NPs@ PAMAM (a,b) and M NPs@PAMAM@RSA (c,d).

\section{Conclusion}

In the present study, magnetite nanoparticles (M NPs) were immobilized into poly (amido amine) (PAMAM) dendrimer in the mother nanocomposite(M NPs @ PAMAM). The M NPs were conjugated with dendrimer matrix through formation of $\mathrm{N}-\mathrm{O}-\mathrm{Fe}$ linkages. This was accompanied with a reduction inmagnetite average particle size from $39.1 \mathrm{~nm}$ (311) in pure M NPs to $27.7 \mathrm{~nm}$ (311) in M NPs @PAMAM. The incorporated M NPs seemed to be embedded in dendrimer matrix, mainly on coreand cavities, in some uneven distribution.

For the hybrid M NPs@PAMAM@RSA, M NPs were conjugated from side with PAMAM through CO-NH linkages and through Si-O- linkages of the RSA. The presence of RSA encouraged intimate interaction with dendrimer branches, through $\mathrm{Si}-\mathrm{OH}$ of the ash and $\mathrm{Fe}-\mathrm{O}-\mathrm{N}$ conjugations; carbon prevailing in composite space appeared almost filling the dendrimer cavities. The M NPsanchored-dendrimer existed as dispersed cubic nanocrystallites embedded in the dendrimer matrix. 


\section{References}

1. Tomalia, D.A., The dendritic state. Maerials Today, 34 (2005).

2. Tomalia, D.A., Baker, H., Dewald, J., Hall, M. and Kallos, G., A new class of polymers:Starburst-dendritic macromolecules. Polymer Journal, 17, 117 (1985).

3. Adam, F., Andas, J. and Rahman, I. A.b., A facile template-free room temperature synthesis of mesoporouswormlike nickel phyllosilicate. The Open Colloid Science Journal, 4, 12 (2011).

4. Munshi, S., Dey, G. and Sharma, R. P., Use of rice straw ash as pozzolanic material in cement mortar. IACSIT International Journal of Engineering and Technology, 5, $603(2013)$.

5. Ficai, D., Andronescu, E., Ficai, A., Voicu, G. and Vasile, B., Synthesis and characterization of mesoporous magnetite based nanoparticles. Current Nanoscience, 8, 875 (2012).

6. Dendrimers and Other Dendritic Polymers. Edited by Jean, M. J. Fre' chet and Donald A. Tomalia Copyright (C) 2001 John Wiley \& Sons Ltd ISBNs: 0-471-638501(Hardback); 0-470-84582-1 (Electronic).

7. Lu, T .T., Yang, L .B. and Liaw, W. F., J. Chin. Chem. Soc. 57, 909 (2010).

8. Kurtan,U., Esir, S., Baykal, A. and Sözeri, H., J. Supercond Nov. Magn. 27, 2097 (2014).

9. Wang, B., Wei, Q. and Qu, S., Synthesis and characterization of uniform and crystalline magnetite nanoparticles via oxidation-precipitation andmodified coprecipitation methods. Int. J. Electrochem Sci, 8, 3786 (2013).

10. Chou, C.M. and Lien, H.L., Dendrimer-conjugated magnetic nanoparticles for removal of zinc (II) from aqueous solutions. J. Nanopart. Res., DOI 10-10071511051010-9967-5 (2010)

11. Hassan, S.A. and El-Salamony, R.A., Photocatalytic disc-shaped composite systems for removalof hazardous dyes in aqueous solutions. Canadian Chemical Transition, 2, 57 (2014).

(Received 4/11/2015;

accepted 11/11/2015)

Egypt. J. Chem. 58, No. 6 (2015) 
Interaction Characteristics Governing the Synthesis of Magnetite Nanoparticls... 697

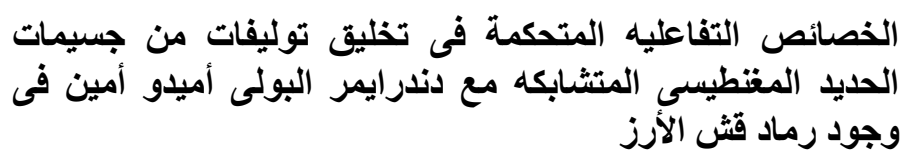

صلاح الدين عبده حسن ، عاطف سمير درويش ، نور الدين أحمد عبد الستار ، ونداء

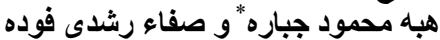

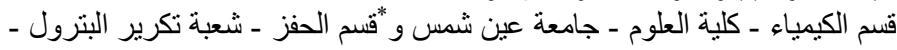

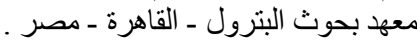

تم فى هذا البحث تحضير توليفة اساسية من جسيمات الماجنيتايت (الحديد

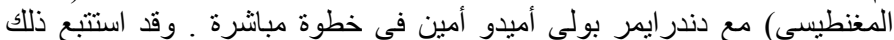

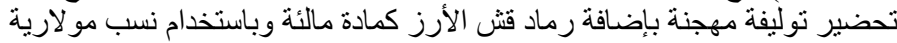

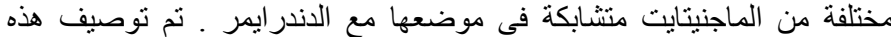

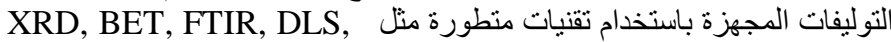

. SEM and TEM

أثبتت الدراسة اشتباك جسيمات الماجنيتايت نانوية الحجم بمجموعات الأمين

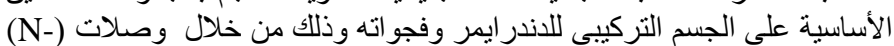

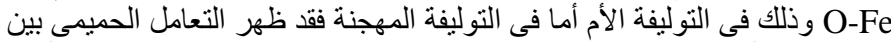

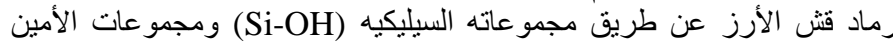

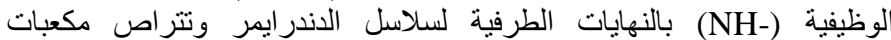

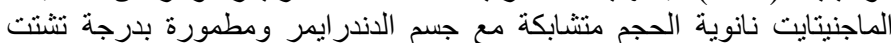

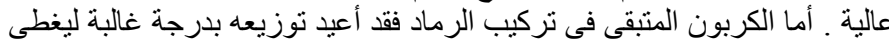

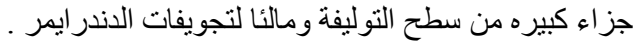

